\section{FDA research}

Barbara Culliton's discussion of US Food and Drug Administration (FDA) research (Nature Med. 3, 477, 1997) may mislead those who have not read the report of the Korn committee she discusses or are unfamiliar with FDA programs. The report identifies serious organizational and management problems, as she points out. However the Korn report (available at www.fda.gov/cber/research.htm) does not state that FDA research is mediocre in general or "fails to make the grade" as Culliton's title claims.

In particular, Culliton says that FDA scientists do not publish regularly in first-ranked, highly competitive international journals, and that they compare poorly with NIH scientists - an opinion contradicted by Joseph Edward Rall, former deputy director for intramural research at $\mathrm{NIH}$ (Science 276, 1319; 1997). As employees at FDA's Center for Biologics Evaluation and Research, we have examined our 1996 bibliography. We found that the staff authored 23 scientific papers in internationally competitive, very highly cited journals (journals with an ISI impact factor of more than ten), and 62 papers in competitive, highly cited journals (with an impact factor of 6-10). Over 200 other listings appeared in the bibliography, including papers in less highly cited fields such as physical chemistry, and many in important specialized journals covering applied work necessary for FDA's regulatory mission.
Although Culliton reports correctly that the Korn commission concluded that the Balkanization of FDA may impair research, her example at the biologics center is confused and ill-chosen. The Laboratory of Bacterial Polysaccharides is part of the Division of Bacterial Products, which is in turn part of the Office of Vaccine Research and Review. These are not separate, parallel units.

Regarding the importance of having such research programs at the FDA, the Korn report says, "The subcommittee unanimously and emphatically affirms that the presence in the FDA of a vigorous, high quality intramural program of scientific research provides the essential foundation of sound regulatory policy and performance...". Funding is an issue and on this subject the Korn report says, "The subcommittee believes strongly that starving the agency's base of intramural scientific expertise must inevitably compromise the quality of review and regulatory activities." We thank Ms. Culliton for calling attention to this subject.

\section{SuZANNE L. EPSTEIN}

9512 Milstead Drive

Bethesda, MD 20817

\section{BASCOM F. ANTHONY \\ 9412 Winterset Drive \\ Potomac, MD 20854}

The opinions expressed are those of the authors and not necessarily those of the FDA. tion with vaccinia virus (VV) strain Kopenhagen. The VV infection resulted in an activation of up to $80 \%$ of the peripheral lymphocytes of the animals (measured by CD25/CD69 expression). However, this strong immune activation did not lead to enhanced replication of the attenuated SIV nor to an onset of immunodeficiencys. Control experiments showed that the replication of undeleted, pathogenic SIV could be enhanced in vivo using the same immune stimulation protocol. Our experiment implies that temporary immune stimulation cannot reactivate attenuated SIV in juvenile animals. The effects of long term immune stimulation remain to be determined.

$\mathrm{We}^{6}$ and others ${ }^{7}$ have observed the reversion of attenuated SIV to virulence due to the repair of small deletions within the SIV nef, in vivo. Paradoxically, when the attenuated SIV that is able to induce protective immunity (against an SIV challenge) in macaques, reverts to a more virulent virus in vivo, the SIV-specific immune response is inefficient and unable to prevent the onset of immunodeficiency in these animals. An understanding of these results is a prerequisite to answering Murphey-Corb's question concerning the safety of live-attenuated HIV vaccines.

\section{ULF DITTMER, \\ Christiane Stahl-HenNig \& \\ GERHARD HUNSMANN \\ German Primate Centre \\ Dept. of Virology and Immunology \\ Kellnerweg 4 \\ 37077 Goettingen, Germany. \\ e-mail: ghunsma@gwdg.de}

\title{
Live HIV vaccines - How safe?
}

To the editor - In a recent issue of Nature Medicine, Wyand et al. ${ }^{1}$ reported neonatal macaques exposed to a live-attenuated SIV vaccine. Although such vaccines seem to be effective and safe in adult monkeys, some of their new data confirms previous findings ${ }^{2}$ that such viruses may be lethal when given in high doses to newborns. This might be due to a state of immune activation in the macaque offspring resulting in an enhanced viral replication. In an accompanying News \& Views, Murphey-Corb suggested that live-attenu- ated SIV may become virulent after immune stimulation of an adult host ${ }^{3}$. This hypothesis can be tested in the SIV model.

During our on-going SIV vaccine experiments, we infected juvenile macaques with an attenuated SIV isolate deleted in the nef gene that conveys protection against pathogenic $\mathrm{SIV}^{4}$. Infection with this attenuated SIV was characterized by a low viral load in the animals. We then tried to enhance the viral replication in these macaques through a systemic immune activation induced by superinfec-
1. Wyand, S.W., Manson, K.H., Lackner, A.A. \& Desrosiers, R.D. Resistance of neonatal monkeys to live attenuated vaccine strains of simian immunodeficieny virus. Nature Med. 3, 32-36 (1997).

2. Baba, T.W. et al. Pathogenicity of live, attenuated SIV after mucosal infection of neonatal macaques. Science 267, 1820-1825 (1995).

3. Murphey-Corb, M. Live-attenuated HIV vaccines: How safe is safe enough? Nature Med. 3, 17-18 (1997).

4. Stahl-Hennig, C. et al. Rapid development of vaccine protection in macaques by live attenuated simian immunodeficiency virus. I. Gen. Virol. 77, 2969-2981 (1996).

5. Dittmer, $U$. et al. No reactivation of attenuated immunodeficiency viruses in macaques after vaccinia virus-induced immune activation. J. Gen. Virol. (in the press).

6. Dittmer, U. et al. Cellular immune response of rhesus monkeys infected with a partially attenuated nef deletion mutant of the simian immunodeficiency virus. Virology 212, 392-397 (1995).

7. Whatmore, A.M. et al. Repair and evolution of nef in vivo modulates simian immunodeficiency virus virulence. J. Virol. 69, 5117-5123 (1995). 